\title{
An Octadentate Luminescent Eu(III) 1,2-HOPO Chelate with Potent Aqueous Stability
}

\author{
Evan G. Moore, Christoph J. Jocher, Jide Xu, Eric J. Werner and Kenneth N. \\ Raymond*
}

Department of Chemistry, University of California, Berkeley, CA, 94720-1460.

RECEIVED DATE (will be automatically inserted after manuscript is accepted)

The synthesis, characterization, and photophysical properties of two novel ligands, $5 \mathrm{LIN}^{\mathrm{Me}}-1,2-\mathrm{HOPO}(\mathbf{1})$ and $\mathrm{H}(2,2)-1,2-\mathrm{HOPO}(2)$, which utilize the 1,2-HOPO chelate as a sensitizer for $\mathrm{Eu}(\mathrm{III})$ are reported. In addition, the former ligand was structurally characterized as the $\mathrm{Eu}(\mathrm{III})$ complex by X-ray crystallography. The $\left[\mathrm{Eu}(\mathbf{1})_{2}\right]^{-}$complex of the tetradentate ligand (1) is stable in aqueous solution, to a limiting concentration of ca. $7 \times 10^{-9} \mathrm{M}$, and retains the superior photophysical performance noted for the 1,2-HOPO sensitizer. By contrast, the octadentate ligand (2) has vastly improved stability as the $[\mathrm{Eu}(2)]^{-}$ complex upon further dilution, to a limiting concentration of ca. $5 \times 10^{-17} \mathrm{M}$, which is beyond the minimum detectable concentration of most fluorimeters. The presence of a single coordinated water molecule for the latter complex reduces the overall metal centered luminescence.

Organic complexes of luminescent lanthanides such as $\mathrm{Eu}(\mathrm{III})$ have become increasingly useful for biological assays and in high throughput screening applications, ${ }^{1,2}$ where their long lived luminescence can allow significant improvement in signal to noise ratio. Several $\mathrm{Ln}(\mathrm{III})$ chelates are commercially available (eg. Lance ${ }^{\mathrm{TM}}$ - Perkin Elmer, LanthaScreen ${ }^{\mathrm{TM}}$ - Invitrogen) and fluorescent assay platforms such as Dissociation-Enhanced Lanthanide Fluorescent Immuno Assay (DELFIA) are well developed, ${ }^{3}$ offering increased sensitivity compared to colorimetric assay formats such as Enzyme-Linked Immuno Sorbent Assay (ELISA). ${ }^{4}$ Nonetheless, the quantum yield of these commercial luminescence agents are far from optimized (ca. 2-10\%), and the improvement of this crucial parameter while maintaining sufficient aqueous solubility and stability for biological compatibility is a challenging area of active current interest. ${ }^{5}$

We recently reported ${ }^{6}$ the exceptional photophysical performance of tetradentate 1-hydroxypyridin-2-one derivatives such as $5 \mathrm{LIO}-1,2-\mathrm{HOPO}(3)$ that form stable
$\mathrm{ML}_{2}$ complexes with $\mathrm{Eu}(\mathrm{III})$. These ligands simultaneously fulfill the criteria of both high thermodynamic stability and excellent photophysical properties. Herein, we extend this family to include an amino linked version $5 \mathrm{LIN}^{\mathrm{Me}}-1,2-$ HOPO (1) (Chart 1) which was developed as a model for $\mathrm{H}(2,2)-1,2-\mathrm{HOPO}(2)$, the first example of an octadentate 1,2-HOPO derivative for $\mathrm{Eu}(\mathrm{III})$ luminescence. The latter forms an ML complex with improved stability upon dilution in aqueous solution, a feature required for the practical development and application of these complexes in biological assays.

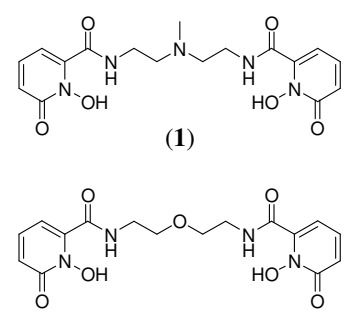

(3)

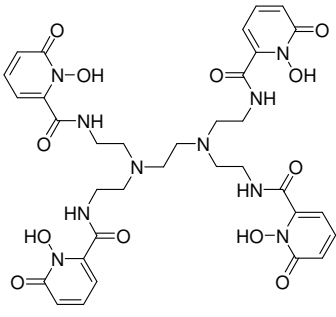

(2)
Chart 1. Structures of 5LIO-1,2-HOPO (3) (top left), $5 \mathrm{LIN}^{\mathrm{Me}}-1,2-\mathrm{HOPO}$ (1) (bottom left) and $\mathrm{H}(2,2)-1,2-\mathrm{HOPO}$ (2) (right).

The syntheses of $5 \mathrm{LIN}^{\mathrm{Me}}-1,2-\mathrm{HOPO}$ and $\mathrm{H}(2,2)-1,2-$ HOPO are straightforward (see Scheme S1, Supp. Info.). Boc amidation of $\mathrm{N}$-(2-aminoethyl)-ethane-1,2-diamine (dien) followed by reductive amination with formaldehyde provides the protected backbone which was converted to the $5 \mathrm{LIN}^{\mathrm{Me}}$ amine by reaction with TFA. Alternately, the $\mathrm{N}, \mathrm{N}, \mathrm{N}$ ',N'-tetrakis-(2-aminoethyl)-ethane-1,2-diamine $(\mathrm{H}(2,2))$ may be prepared using literature methods. ${ }^{7}$ Reaction of either backbone with the thiazaolide activated 1,2-HOPO precursor ${ }^{6,8}$ yields the benzyl protected ligands, which were deprotected under acidic conditions with 1:1 (v/v) AcOH:HCl (12 M). Complexation with $\mathrm{EuCl}_{3} \cdot 6 \mathrm{H}_{2} \mathrm{O}$ in $\mathrm{MeOH}$ at reflux gave the desired complexes on cooling in good yield and analytically pure form. An X-ray quality crystal of the $\left[\mathrm{Eu}\left(5 \mathrm{LIN}^{\mathrm{Me}}-1,2-\mathrm{HOPO}\right)_{2}\right]^{-}$complex, as the potassium salt, was grown by slow evaporation of a $c a$. $500 \mu \mathrm{M}$ solution in $0.1 \mathrm{M} \mathrm{KCl}$ at $c a$. $\mathrm{pH} 8$.

As shown in Figure 1, the anion Eu(III) complex of (1) forms an $\mathrm{ML}_{2}$ species, with an overall eight coordinate

\footnotetext{
* To whom correspondence should be addressed. Email: raymond@ socrates.berkeley.edu. Fax (Int.) +1 (510) 4865283
} 


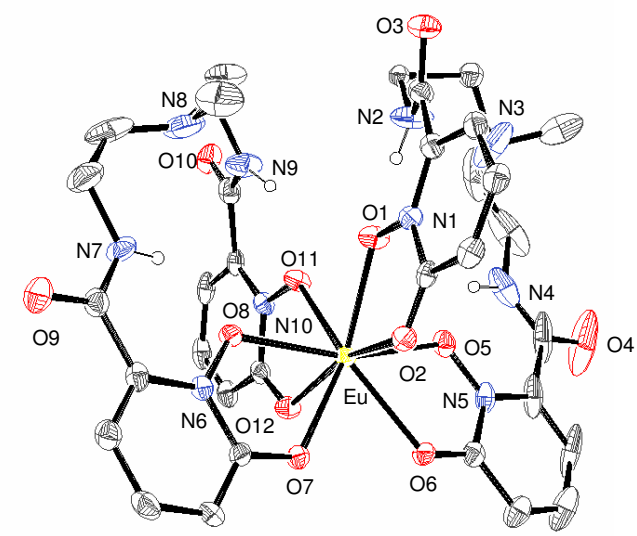

Figure 1. X-ray structure of $\left[\mathrm{Eu}\left(5 \mathrm{LIN}^{\mathrm{Me}}-1,2-\mathrm{HOPO}\right)_{2}\right]^{-}(30 \%$ probability ellipsoids shown, Ortep 3). Solvent molecules, potassium counter cation and selected $\mathrm{H}$ atoms have been omitted for clarity. Only one orientation of the disordered ligand backbone is shown.

central metal ion. Shape analysis, as discussed elsewhere, ${ }^{9,10}$ was used to assess the closest idealized coordination polyhedra, yielding the best fit to an approximate $\mathrm{C}_{2 v}$ geometry at the metal (see Table S1). Notably, the observed geometry is very similar to that previously reported ${ }^{6}$ for the structurally analogous ligand (3) with an ether linkage in the backbone. In the present case, as with the $\left[\operatorname{Eu}(3)_{2}\right]^{-}$structure, the presence of four intramolecular hydrogen bonding interactions is noted between the amide nitrogen protons and proximal phenolic oxygen atoms (avg. $\mathrm{N}-\mathrm{H}---\mathrm{O}=1.97 \AA$ ). These interactions have been noted in several previous examples, ${ }^{6,8}$ and impart additional stability to the ensuing metal complex. A potassium counter cation was also located at the base of each $\mathrm{Eu}(\mathrm{III})$ complex, which forms a trifurcated interaction with the $\mathrm{O} 2$, O6, and $\mathrm{O} 7$ oxygens of the anionic complex, and is bridged by amide carbonyl oxygens from three adjacent molecules $(\mathrm{O} 3, \mathrm{O} 9$, and $\mathrm{O} 10)$ to form an extended coordination polymer network. The coordination sphere of the potassium ion is completed by a solvent water molecule, yielding an overall 7 coordinate cation (see Figure S1).

Ligand $\mathrm{pK}_{\mathrm{a}}$ 's for (1) and (2) were determined by potentiometry, and resulting values are summarized in Tables 1 and 2. For both ligands, the most basic protonation sites were assigned to the amine nitrogen atoms by comparison to previous reports. ${ }^{6}$ For the $\left[\mathrm{Eu}(\mathbf{1})_{2}\right]^{-}$complex, a formation constant of $\log \beta_{120}=23.0$ (1) was determined from the conditional stability constant $\left(\mathrm{pEu}^{7.4}=17.3(1)\right)$, obtained by competition batch titration versus DTPA (see Figure S2). ${ }^{6}$ Subsequent potentiometric titrations could be refined with fixed ligand protonation constants and a fixed $\log \beta_{120}=23.0$, resulting in $\log \beta_{121}=30.5$ (5), $\log \beta_{122}=$ 36.97 (5), and $\log \beta_{123}=41.5$ (1), with initial protonation sites of the metal complex most likely located at the basic amine functions, and a third (most acidic) protonation at one of the 1,2-HOPO chromophores. Preliminary stability data for the octadentate complex, $[\mathrm{Eu}(\mathbf{2})]^{-}$, was also determined via competition batch titration versus DTPA at $\mathrm{pH} 7.4$, yielding a pEu of 21.2 (1). Potentiometric titrations were hampered by a decrease in solubility of the complex below $\mathrm{pH} 7$ (from $>0.5 \mathrm{mM}$ to $\sim 0.1 \mathrm{mM}$ ), which thwarted refinement of the titration data. Instead, additional competition batch titration versus DTPA at $\mathrm{pH} 6.1$ and 8.5 were performed (see Figure S3). Values of $\log \beta_{110}=21.8$ (5), $\log \beta_{111}=31.2$ (3) and $\log \beta_{112}=38.1$ (2) resulted from fits to these data, along with $[\mathrm{Eu}(2)]^{-}$complex protonation constants of $\mathrm{pK}_{\mathrm{a} 1}=9.4$ (5) and $\mathrm{pK}_{\mathrm{a} 2}=6.9$ (2) which, by analogy to $\left[\operatorname{Eu}(\mathbf{1})_{2}\right]^{-}$, we assign to protonation of the amine backbone nitrogens. The complete solution thermodynamic model is described by the parameters summarized in Table 2. Assuming a tolerance of $1 \%$ free $\mathrm{Eu}(\mathrm{III})$, we calculate a theoretical stability limit for the $[\mathrm{Eu}(2)]^{-}$complex of $c a$. $5 \times 10^{-17} \mathrm{M}$ at $\mathrm{pH} 7.4$ in the absence of competing species (Figure 2), whereupon further dilution leads to hydrolysis of the complex. This limiting concentration is some eight orders of magnitude improved when compared to the corresponding calculation for $\left[\operatorname{Eu}(\mathbf{1})_{2}\right]^{-}$, which yields a limiting concentration of $c a .7 \times 10^{-9} \mathrm{M}$ (see Figure S4), demonstrating the dramatic enhancement of stability at high dilution due primarily to the entropic chelate effect when moving from a tetradentate to octadentate ligand topology.

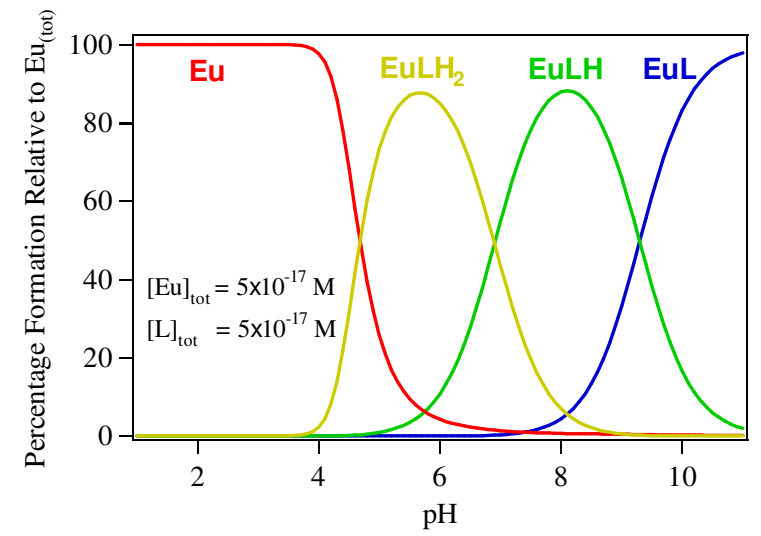

Figure 2. Speciation diagram for $[\mathrm{Eu}(\mathrm{H}(2,2)-1,2-\mathrm{HOPO})]$ in aqueous solution, illustrating the excellent thermodynamic stability of the complex upon very high dilution at ca. $5 \times 10^{-17} \mathrm{M}$.

Table 1. Protonation and $\mathrm{Eu}(\mathrm{III})$ complex formation constants of $5 \mathrm{LIN}^{\mathrm{Me}}-1,2-\mathrm{HOPO}$ compared to previously reported ${ }^{6} 5 \mathrm{LIO}-1,2-\mathrm{HOPO}$.

\begin{tabular}{|l|c|c|}
\cline { 2 - 3 } \multicolumn{1}{c|}{} & 5LIN $^{\mathrm{Me}}$-1,2-HOPO & 5LIO-1,2-HOPO \\
\hline$p K_{1}$ & $3.76(3)$ & $4.19(3)$ \\
\hline$p K_{2}$ & $5.31(1)$ & $5.79(1)$ \\
\hline$p K_{3}$ & $8.13(1)$ & N/A \\
\hline$p \mathrm{Eu}^{7.4}$ & $17.3(1)$ & $18.6(1)$ \\
\hline $\log \beta_{120}$ & $23.0(1)$ & $22.9(1)$ \\
\hline $\log \beta_{121}$ & $30.5(5)$ & $25.2(3)$ \\
\hline $\log \beta_{122}$ & $36.97(5)$ & N/A \\
\hline $\log \beta_{123}$ & $41.5(1)$ & N/A \\
\hline
\end{tabular}

Table 2. Protonation and Eu(III) complex formation constants of H(2,2)-1,2-HOPO.

\begin{tabular}{|c|c|c|c|}
\hline$p K_{1}$ & $3.19(4)$ & $\mathrm{pEu}^{8.5}$ & $21.7(1)$ \\
\hline$p K_{2}$ & $4.27(3)$ & $\mathrm{pEu}^{7.4}$ & $21.2(1)$ \\
\hline$p K_{3}$ & $5.23(3)$ & $\mathrm{pEu}^{6.1}$ & $20.0(1)$ \\
\hline$p K_{4}$ & $6.22(2)$ & $\log \beta_{110}$ & $21.8(5)$ \\
\hline$p K_{5}$ & $7.77(1)$ & $\log \beta_{111}$ & $31.2(3)$ \\
\hline$p K_{6}$ & $10.43(2)$ & $\log \beta_{112}$ & $38.1(2)$ \\
\hline
\end{tabular}

The electronic absorption spectra for the $[\mathrm{Eu}(2)]^{-}$and $\left[\operatorname{Eu}(\mathbf{1})_{2}\right]^{-}$complexes are shown in Figure 3 and S5 respectively, and are typical of that observed for the 1,2-HOPO chromophore, ${ }^{6}$ comprising an $n-\pi^{*}$ transition at ca. $330-340 \mathrm{~nm}$ and more intense $\pi-\pi^{*}$ bands to higher energy. Notably, the spectrum of $[\mathrm{Eu}(\mathbf{2})]^{-}$has a slightly red 
Table 3. Summary of experimental and calculated photophysical parameters for $\left[\mathrm{Eu}\left(5 \mathrm{LIN}^{\mathrm{Me}}-1,2-\mathrm{HOPO}\right)_{2}\right]^{-}$and $[\mathrm{Eu}(\mathrm{H}(2,2)-1,2-\mathrm{HOPO})]^{-}$complexes.

\begin{tabular}{|c|c|c|c|c|c|c|c|}
\hline Complex & $\begin{array}{c}\lambda_{\max }, \varepsilon_{\max } \\
\left(\mathrm{nm}, \mathrm{M}^{-1} \mathrm{~cm}^{-1}\right)\end{array}$ & $\Phi_{\text {tot }}\left(\mathrm{H}_{2} \mathrm{O}\right)$ & $\begin{array}{c}\tau_{\text {obs }} \mathrm{H}_{2} \mathrm{O},\left\{\mathrm{D}_{2} \mathrm{O}\right\} \\
(\mu \mathrm{sec})\end{array}$ & $\begin{array}{c}k_{\mathrm{r}}, \text { calc'd }^{\prime} \\
\left(\mathrm{ms}^{-1}\right)\end{array}$ & $\begin{array}{c}k_{\mathrm{nr}}, \text { calc'd } \\
\left(\mathrm{ms}^{-1}\right)\end{array}$ & $\Phi_{\mathrm{Eu}}$, calc'd & $\eta_{\text {sens }}$, calc'd \\
\hline$\left[\mathrm{Eu}\left(5 \mathrm{LIN}^{\mathrm{Me}}-1,2-\mathrm{HOPO}\right)_{2}\right]$ & 332,18750 & $0.173 \pm 0.026$ & $728 \pm 2.8\{1000 \pm 2.5\}$ & 0.61 & 0.77 & 0.442 & 0.391 \\
\hline$[\mathrm{Eu}(\mathrm{H}(2,2)-1,2-\mathrm{HOPO})]$ & 341,18200 & $0.036 \pm 0.005$ & $480 \pm 1.2\{1222 \pm 2.5\}$ & 0.38 & 1.75 & 0.178 & 0.202 \\
\hline
\end{tabular}

shifted $\lambda_{\max }$ at $341 \mathrm{~nm}, c a .800 \mathrm{~cm}^{-1}$ lower than the $\left[\operatorname{Eu}(\mathbf{1})_{2}\right]^{-}$complex. The luminescence spectra of $[\mathrm{Eu}(\mathbf{2})]^{-}$is also shown in Figure 3, and is typical of that for the Eu(III) cation in a low symmetry environment (vide infra).

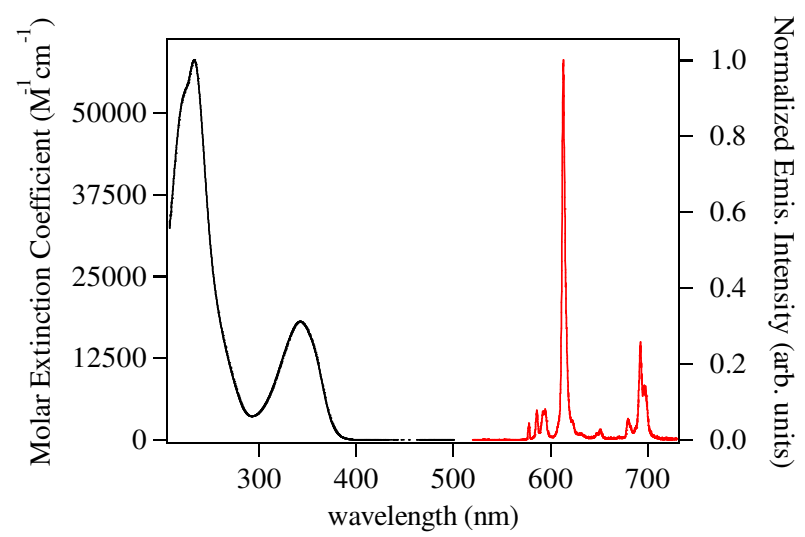

Figure 3. Electronic absorption spectrum (left) and steady state emission spectrum (right) $\left(\lambda_{\mathrm{ex}}=340 \mathrm{~nm}, 5 \mathrm{~nm}\right.$ bandpass) of $5 \mu \mathrm{M}[\mathrm{Eu}(2)]^{-}$in $0.1 \mathrm{M}$ TRIS buffer at $\mathrm{pH} 7.4$

A summary of the relevant photophysical parameters determined experimentally (and calculated from the emission spectrum as discussed elsewhere ${ }^{11}$ ) for $\left[\operatorname{Eu}(\mathbf{1})_{2}\right]^{-}$ and $[\operatorname{Eu}(2)]^{-}$is given in Table 3. Most notably, while the quantum yield of $\left[\mathrm{Eu}(\mathbf{1})_{2}\right]^{-}$is comparable to that previously reported $^{6}$ for the analogous $\left[\operatorname{Eu}(3)_{2}\right]^{-}$complex, the corresponding value of $\Phi_{\text {tot }}=3.6 \pm 0.5 \%$ for $[\mathrm{Eu}(2)]^{-}$is almost an order of magnitude less than the tetradentate model compounds.

The corresponding luminescence lifetimes were evaluated for both complexes in aqueous and deuterated solvent, allowing the degree of hydration, $q$, to be estimated using the recently improved Horrocks equation. ${ }^{12}$ The resulting $q$ values for $\left[\mathrm{Eu}(\mathbf{1})_{2}\right]^{-}$and $[\operatorname{Eu}(\mathbf{2})]^{-}$were 0.07 and $1.06 \pm 0.1$ respectively. Accordingly, while $\left[\operatorname{Eu}(\mathbf{1})_{2}\right]^{-}$ receives an effective degree of protection from nonradiative deactivation by solvent interactions, it appears the $[\mathrm{Eu}(2)]^{-}$complex retains a single bound water molecule in the metals first coordination sphere. Since the radiative decay rate of the $\mathrm{Eu}$ (III) cation is known ${ }^{12}$ to be strongly influenced by the presence of proximal $\mathrm{OH}$ oscillators, which explains the poor photophysical performance for $\left[\mathrm{Eu}(\mathbf{2})\left(\mathrm{H}_{2} \mathrm{O}\right)\right]^{-}$. Furthermore, it appears both the radiative decay rate, $k_{\mathrm{r}}$, and the energy transfer efficiency (from ligand to metal), $\eta_{\text {sens }}$, are lower for $\left[\operatorname{Eu}(2)\left(\mathrm{H}_{2} \mathrm{O}\right)\right]^{-}$for reasons which are not yet readily apparent and are currently being investigated.

Lastly, it has been shown ${ }^{13}$ that the observed emission spectra can be used to yield an insight into the solution structure of $\mathrm{Eu}(\mathrm{III})$ complexes. The corresponding $q$ measurements determined a nine coordinate coordination polyhedra for $\left[\mathrm{Eu}(2)\left(\mathrm{H}_{2} \mathrm{O}\right)\right]^{-}$. However, a consideration of the symmetry allowed transitions (see Table S3) did not yield a satisfactory match to either the tricapped trigonal prismatic $\left(\mathrm{D}_{3 \mathrm{~h}}\right)$ or monocapped square antiprismatic $\left(\mathrm{C}_{4 \mathrm{v}}\right)$ geometries. Rather, a closer analysis of the $\mathrm{J}=1$ band reveals a splitting of the degenerate $\mathrm{E}$ state of the latter into two $2 \mathrm{~B}$ bands (see Figure S6), consistent with a local $\mathrm{C}_{2}$ site symmetry for the metal ion. ${ }^{13}$ This can be rationalized by the $\mathrm{C}_{2}$ geometry enforced by the ligand. An optimized MM3 model of the $\left[\mathrm{Eu}(\mathbf{2})\left(\mathrm{H}_{2} \mathrm{O}\right)\right]^{-}$complex is shown in Figure 4 and supports this assignment.
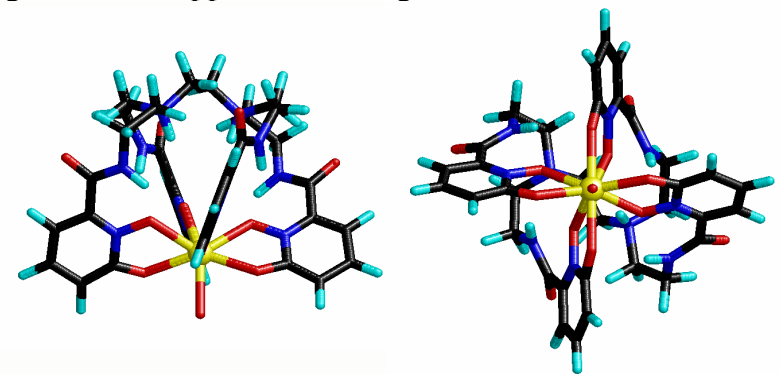

Figure 4. Side view (left) and bottom view (right) of an MM3 optimized geometry for the $\left[\mathrm{Eu}(2)\left(\mathrm{H}_{2} \mathrm{O}\right)\right]^{-}$complex demonstrating local $\mathrm{C}_{2}$ symmetry about the $\mathrm{Eu}(\mathrm{III})$ metal ion.

Our efforts are now turning toward eliminating the residual water molecule in order to improve the luminescent characteristics of these octadentate 1,2-HOPO derivatives.

Acknowledgment. This work was supported by the NIH (Grant HL69832) and the Director, Office of Science, Office of Advanced Scientific Computing Research, Office of Basic Energy Sciences (U.S. Department of Energy) under contract DE-AC02-05CH11231. Financial support was provided to C.J.J. by the German Research Foundation (DFG). The authors thank Dr. Michael Seitz for assistance with the collection of X-ray data.

Supporting Information Available: Synthesis of $5 \mathrm{LIN}^{\mathrm{Me}}-1,2$ HOPO, H(2,2)-1,2-HOPO, and Eu(III) complexes. Shape analysis results and crystal data (cif) for $\left[\mathrm{K}\left(\mathrm{H}_{2} \mathrm{O}\right) \mathrm{Eu}(\mathbf{1})_{2}\right] \cdot \mathrm{H}_{2} \mathrm{O}$. Details of solution thermodynamic experiments and photophysical data. This material is available free of charge via the Internet at http://pubs.acs.org.

\section{References}

1. Yuan, J.; Wang, G., Trends Anal. Chem., 2006, 25, 490-500.

2. Hemmila, I., J. Biomol. Screen., 1999, 4, 303-307.

3. Hemmila, I. A., Immunochem., 1997, 193-214.

4. Allicotti, G.; Borras, E.; Pinilla, C., J. Immunoassay Immunochem., 2003, 24, 345-358.

5. Petoud, S.; Cohen, S. M.; Buenzli, J.-C. G.; Raymond, K. N., J. Am. Chem. Soc., 2003, 125, 13324-13325.

6. Moore, E. G.; Xu, J.; Jocher, C. J.; Werner, E. J.; Raymond, K. N., J. Am. Chem. Soc., 2006, 128, 10648-10649.

7. Wagnon, B. K.; Jackels, S. C., Inorg. Chem., 1989, 28, 1923-7.

8. Xu, J.; Churchill, D. G.; Botta, M.; Raymond, K. N., Inorg. Chem., 2004, 43, 5492-5494.

9. Kepert, D. L., Prog. Inorg. Chem., 1978, 24, 179-249.

10. Xu, J.; Radkov, E.; Ziegler, M.; Raymond, K. N., Inorg. Chem., 2000, 39, 4156-4164.

11. Werts, M. H. V.; Jukes, R. T. F.; Verhoeven, J. W., Phys. Chem. Chem. Phys., 2002, 4, 1542-1548.

12. Supkowski, R. M.; Horrocks, W. D., Jr., Inorg. Chim. Acta, 2002, 340, 44-48.

13. Murray, G. M., Sarrio, R. V., Peterson, J. R., Inorg. Chim. Acta. 1990, 176, 233-240. 


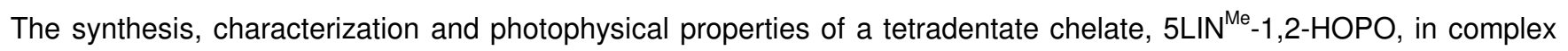
with $\mathrm{Eu}(\mathrm{III})$, are reported. This compound was designed as a model for H(2,2)-1,2-HOPO, (the 'red-back spider' 'Latrodectus Hasselti), an octadentate ligand which delivers strong red emission in complex with Eu(III) upon ligand centered excitation and demonstrates potent aqueous stability upon extremely high dilution to a theoretical limiting concentration of $5 \times 10^{-17} \mathrm{M}$.
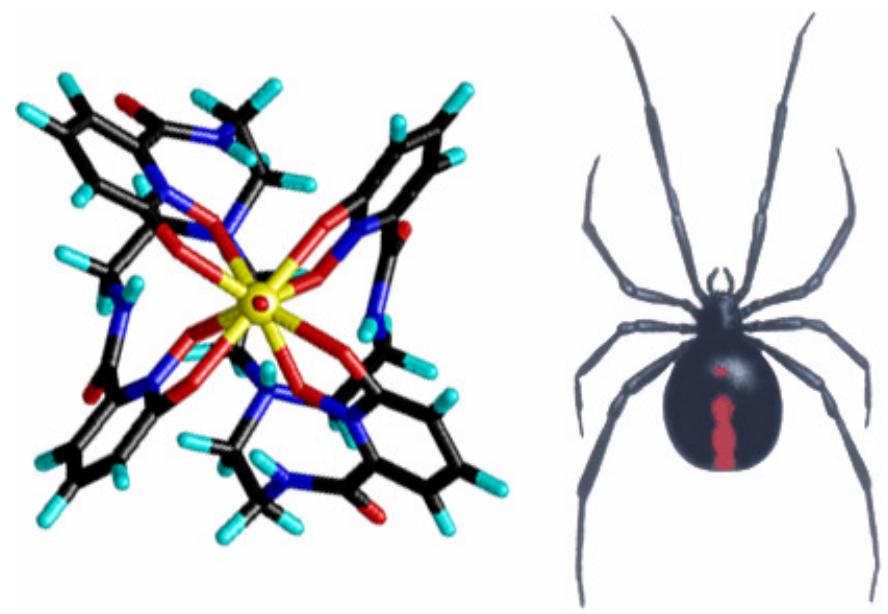